\title{
Manganese zinc ferrite nanoparticles as efficient catalysts for wet peroxide oxidation of organic aqueous wastes
}

\author{
MANJU KURIAN* and DIVYA S NAIR \\ Department of Chemistry, Mar Athanasius College, Kothamangalam, 686666, India \\ e-mail:mk@macollege.in
}

MS received 6 March 2014; revised 20 September 2014; accepted 24 September 2014

\begin{abstract}
Manganese substituted zinc nanoparticles, $\mathrm{Mn}_{\mathrm{x}} \mathrm{Zn}_{1-\mathrm{x}} \mathrm{Fe}_{2} \mathrm{O}_{4}(\mathrm{x}=0.0,0.25,0.5,0.75,1.0)$ prepared by sol gel method were found to be efficient catalysts for wet peroxide oxidation of 4-chlorophenol. Complete degradation of the target pollutant occurred within $90 \mathrm{~min}$ at $70^{\circ} \mathrm{C}$. Zinc substitution enhanced the catalytic efficiency and the unsubstituted $\mathrm{ZnFe}_{2} \mathrm{O}_{4}$ oxidized the target compound completely within $45 \mathrm{~min}$. Studies on the effect of reaction variables revealed that only a small amount of the oxidant, $\mathrm{H}_{2} \mathrm{O}_{2}(3-4 \mathrm{~mL})$ is required for complete degradation of 4-chlorophenol. More than $80 \%$ of 4-chlorophenol was removed at catalyst concentrations of $100 \mathrm{mg} / \mathrm{L}$. Direct correlation between the amount of catalyst present and the extent of degradation of 4-chlorophenol was observed, ruling out hesterogeneous-homogeneous mechanism. The catalysts are reusable and complete degradation of target pollutant occurred after five successive runs. The extent of iron leaching was fairly low after five consecutive cycles indicating the mechanism to be heterogeneous.
\end{abstract}

Keywords. Spinel ferrites; catalytic activity; wet peroxide oxidation; 4-chlorophenol; water treatment.

\section{Introduction}

Sustainable waste water management and reuse of industrial waste water are critical issues for the development of human activities and environment conservation. The treatment and safe disposal of hazardous organic waste material in an environmentally acceptable manner and at a reasonable cost is a topic of great importance. Biological processes are employed as baseline treatment for most organic waste in water since they fulfil the two criteria mentioned before. However, these processes do not always give satisfactory results, since many organic compounds are inhibitory, toxic or resistant to biological treatment. In some cases, even in biological systems adapted for the toxicity, high variation of organic charge can generate negative effects during treatment, causing the emission of undesirable amounts of toxic products in the treated waste water. Coupling chemical pre-oxidation with biological post treatment would be beneficial since it can lead to increased treatment efficiencies. Nowadays, chemical oxidation processes are focused on giving partially oxidized effluents containing readily biodegradable compounds that allow its combination with biological treatment. Advanced Oxidation Processes (AOPs), defined as aqueous phase oxidation processes based on

*For correspondence the use of hydroxyl radical as oxidant are attractive chemical techniques for the destruction of organic pollutants during water treatment. ${ }^{1,2}$ Wet Air Oxidation (WAO) and Wet Peroxide Oxidation (WPO) are two major techniques that come under this category. In Wet Air Oxidation, the degradation rate is strongly limited by the mass transfer of molecular oxygen from the gas to the liquid phase. Wet Peroxide Oxidation takes advantage of using hydrogen peroxide as the liquid oxidant, which avoids gas-liquid mass transfer limitations. The severe operation conditions of WAO make it more capital intensive whereas WPO demands a lower capital. In WPO, hydroxyl radicals can be produced from $\mathrm{H}_{2} \mathrm{O}_{2}$ using homogeneous methods such as Fenton reaction ${ }^{3,4}$ or heterogeneous catalysts like metal oxides, clays, supported metal catalysts, etc. ${ }^{5,6}$ Application of homogeneous Fenton reaction demands acidification of the water (optimal $\mathrm{pH}$ around 3 ) and involves additional contamination of the treated water by iron and mineral acids. Heterogeneous catalytic wet peroxide oxidation has several advantages over the classical homogeneous Fenton like processes such as enhancement of catalytic activity, lack of secondary pollution and the possibility of reuse of catalyst in successive cycles.

Chlorophenols (CPs) are a group of priority toxic pollutants listed by the US EPA in the Clean Water Act and by the European Union Decision, due to their high toxicity and low biodegradability. They are released 
into water as waste generated from industrial activities like petrochemical, pharmaceutical, wood preserving, plastic, pesticide and herbicide use. ${ }^{7}$ They can also be produced by environmental degradation of more complex molecules like chlorophenoxy acetic acids and chlorobenzenes. Due to their numerous origins, chlorophenols can be found in ground water, wastewater and soils and even in trophic chain of places with very low pollution levels. In people, developmental, behavioural, neurologic, endocrinal, reproductive and immunologic adverse health effects have been linked to these compounds as they are considered to act as uncouplers to oxidative dephosphorylation. ${ }^{8}$ They persist for long periods of time in the environment and can be biomagnified through the food chain. The importance of phenolic industrial effluents besides from their potential toxicity is increased by the high quantities that are disposed eventually. Among chlorophenols, those with chlorine in the $4^{\text {th }}$ position are more toxic than others. Biological treatment has low removal efficiency and thermal and chemical treatments have been developed in the last few years for the detoxification of these organic pollutants.

Ferrites are ceramic ferromagnetic materials with general chemical formula $\mathrm{M}^{\mathrm{II}} \mathrm{Fe}_{2}^{\mathrm{III}} \mathrm{O}_{4}$ where $\mathrm{M}$ represents a metallic cation like Fe, Mn, Mg, Ni, Co, Zn, Cu, $\mathrm{Al}$ or a mixture of these. They crystallize into the spinel structure in which, the sites occupied by the cations are of two types: tetrahedral (Td) and octahedral (Oh) sites. Spinel ferrites have been intensively studied due to their applicability in broad areas like high density information storage systems, ferrofluid technology, magnetocaloric refrigeration, medical diagnostics, gas sensors, guided drug delivery, etc., owing to unique characteristics like large magnetocrystalline anisotropy, high coercivity, high Curie temperature, large magnetostrictive coefficient, chemical stability, corrosion resistance and mechanical hardness. ${ }^{9,10}$ Recently ferrite research has been shifted towards developing these materials in nanometric scales as the performance in their conventional bulk preparation routes is reaching their limits due to their higher electrical conductivity and domain wall resonance. They have well-established catalytic properties also for reactions like decomposition of alcohols and hydrodesulphurization of petroleum crude. These properties depend on the charge on the cation, the nature of the metallic cation and the site distribution of cations among $\mathrm{Td}$ and $\mathrm{Oh}$ sites. In spinels, the octahedral sites are almost exclusively exposed in the crystallites and catalytic activity is mainly due to octahedral cations. ${ }^{11}$ Since the ferrite nanoparticles are magnetic, these can be easily removed from the reaction mixture after catalysis by magnetic methods. Prospective applications of ferrites as green oxidation catalysts for the removal of persistent organic pollutants can be predicted due to the thermal stability and the variable oxidation states of the metal ions.

The present paper probes the feasibility of using mixed ferrite nanoparticles for the degradation of organic aqueous wastes using peroxide oxidation taking 4-chlorophenol as the model compound. A series of ferrospinels viz. $\mathrm{Mn}_{\mathrm{x}} \mathrm{Zn}_{1-\mathrm{x}} \mathrm{Fe}_{2} \mathrm{O}_{4}(\mathrm{x}=0,0.25,0.5,0.75$ and 1) was prepared by sol-gel auto combustion method using ethylene glycol as the gelating agent. Liquid phase catalytic peroxide oxidation of 4-chlorophenol under mild conditions was studied in detail using both Gas Chromatography (GC) and Chemical Oxygen Demand (COD) measurements. The process was optimized with respect to different reaction variables like time, temperature, 4-chlorophenol concentration, peroxide concentration and catalyst concentration. The reusability of the catalysts for five consecutive cycles was investigated and the possibility of iron leaching was checked using Atomic Absorption Spectrometer (AAS). The prepared catalysts were characterized by X-ray Diffraction (XRD) and Transmission Electron Microscopy (TEM) and X-ray Fluorescence (XRF).

\section{Experimental}

Pure (99.9\%) $\mathrm{Fe}\left(\mathrm{NO}_{3}\right)_{3} .9 \mathrm{H}_{2} \mathrm{O}, \quad \mathrm{Zn}\left(\mathrm{NO}_{3}\right)_{2} \cdot 6 \mathrm{H}_{2} \mathrm{O}$, $\mathrm{Mn}\left(\mathrm{NO}_{3}\right)_{2} \cdot 6 \mathrm{H}_{2} \mathrm{O}$ and ethylene glycol from Merck, India were used as starting materials without further purification. The mixed spinels of $\mathrm{Mn}_{\mathrm{x}} \mathrm{Zn}_{1-\mathrm{x}} \mathrm{Fe}_{2} \mathrm{O}_{4}$ $(\mathrm{x}=0,0.25,0.5,0.75,1.0)$ were prepared by the sol-gel auto combustion method. Required stoichiometric ratio of $\mathrm{Fe}\left(\mathrm{NO}_{3}\right)_{3} \cdot 9 \mathrm{H}_{2} \mathrm{O}, \mathrm{Mn}\left(\mathrm{NO}_{3}\right)_{2} \cdot 6 \mathrm{H}_{2} \mathrm{O}$ and $\mathrm{Zn}\left(\mathrm{NO}_{3}\right)_{2} \cdot 6 \mathrm{H}_{2} \mathrm{O}$ were dissolved in minimum amount of ethylene glycol at room temperature and heated at $60^{\circ} \mathrm{C}$ to obtain a wet gel. This gel dried at $120^{\circ} \mathrm{C}$ selfignited to form a fluffy product which was calcined at $400^{\circ} \mathrm{C}$ for $4 \mathrm{~h}$ to achieve transformation into spinel phase. The ferrite powder was then sieved through a $90 \mathrm{~mm}$ mesh. The prepared ferrite compositions were $\mathrm{ZnFe}_{2} \mathrm{O}_{4}, \mathrm{Mn}_{0.25} \mathrm{Zn}_{0.75} \mathrm{Fe}_{2} \mathrm{O}_{4}, \mathrm{Mn}_{0.5} \mathrm{Zn}_{0.5} \mathrm{Fe}_{2} \mathrm{O}_{4}$, $\mathrm{Mn}_{0.75} \mathrm{Zn}_{0.25} \mathrm{Fe}_{2} \mathrm{O}_{4}$ and $\mathrm{MnFe}_{2} \mathrm{O}_{4}$.

Phase identification of the prepared particles were performed using Bruker AXS D8 Advance X-ray diffractometer with $\mathrm{Cu} \mathrm{K}_{\alpha}(\lambda=1.5406 \AA)$ as the radiation source. The average crystallite size (D) of the ferrite particles was determined from $\mathrm{X}$-ray diffractograms using the Debye- Scherer formula: $\mathrm{D}_{(\mathrm{hkl})}=0.9 \lambda / \beta \cos$ $\theta$ where, $\mathbf{D}_{\text {(hkl) }}$ is the average crystallite size $(\mathrm{nm}), \lambda$ is the wavelength $(\mathrm{nm}), \beta$ is the full width at half maximum (radian) and $\theta$ is the Bragg angle. The lattice 
parameter ' $a$ ' was calculated using the relation, $\mathrm{a}=$ $d\left(h^{2}+k^{2}+l^{2}\right)^{1 / 2}$. Since each primitive unit cell of the spinel structure contains 8 molecules; X-ray density $\left(d_{x}\right)$ was calculated according to the relation $d_{x}=$ $8 \mathrm{M} / \mathrm{Na}^{3}$ where, $\mathrm{N}$ is Avogadro number and $\mathrm{M}$ is molecular weight of the sample. The measured density or bulk density $\left(\mathrm{d}_{\mathrm{B}}\right)$ was calculated from mass and bulk volume of the sample pellets using the formula, $d_{B}=m / \pi r^{2} h$ where, $m$ is the mass of the sample taken, $r$ is the radius of the sample pellet and $\mathrm{h}$ is the height of the pellet. From the bulk density and X-ray density, porosity, P of the ferrite nano particle was determined using the relation, $\mathrm{P}=1-\left(\mathrm{d}_{\mathrm{B}} / \mathrm{d}_{\mathrm{X}}\right)$. The particle size, distribution of nanoparticles and surface morphology were confirmed using PHILIPS Model CM 200 Transmission Electron Microscope with a resolution of 2.4 A with the help of Image J software. Stoichiometry of prepared catalysts was verified using Bruker PIONEER model X-ray fluorescence spectrometer.

Wet peroxide oxidation of 4-chlorophenol was studied in liquid phase, in a $250 \mathrm{~mL}$ two- necked round bottomed flask equipped with a water condenser, thermometer and magnetic stirrer. The reaction mixture was allowed to equilibrate at $70^{\circ} \mathrm{C}$ prior to the initiation of the reaction. Liquid samples were periodically withdrawn from the reaction mixture and quantitatively analyzed using Perkin Elmer Clarus 580 Gas Chromatograph operational with an Elite-5 capillary column and Flame Ionization Detector. The products were identified by GC MS analysis on a Varian 1200 L Single Quadrupole using $\mathrm{He}$ as the carrier gas. The removal (\%) was calculated as the total amount of chlorophenol transformed into products. The extent of oxidation was also studied using Chemical Oxygen Demand measurements employing standard dichromate method. The error percentage between the results of analysis was less than $5 \%$. The influence of various reaction variables like nature of the catalyst and its dosage, substrate concentration, reaction temperature, time, oxidant concentration etc was studied in detail. The reusability of the catalyst was checked for five consecutive cycles and the amount of iron leached during this was quantified using Perkin Elmer Analyst 700 Atomic Absorption Spectrophotometer.

\section{Results and Discussion}

\subsection{Characterization of manganese zinc nanoferrites}

Recording X-ray diffraction pattern of powdered polycrystalline samples by powder diffractometer method has many applications like qualitative phase analysis, quantitative phase analysis, determination of unit cell parameters, study of preferred orientation and determination of particle size. X-ray diffractograms of the manganese zinc ferrites agree closely with the standard values given in the JCPDS data cards (79-1150, 52-0278), confirming the single phase spinel formation (figure 1). Well-defined and broad diffraction peaks corresponding to characteristic crystallographic planes like (220), (311), (400), (422), (511) and (440) of the spinel structure can be observed in the figures. The strongest reflection comes from the (311) plane, which corresponds to cubic spinel structure. The mixed ferrospinels are treated as solid solutions obtained by the substitution of manganese ferrites with zinc ions. In interpreting the XRD profile of such substitutions, the substitutional site can be considered as occupied by a composite atom made up of appropriate portions of the involved atoms, statistically. ${ }^{12,13}$ Hence the XRD profile of the substituted samples is expected to be intermediate between those of the pure substances. XRD patterns of the mixed ferrites are identical with those of manganese ferrite proving that zinc substitution does not change the spinel ferrite structure of manganese ferrite.

The different parameters calculated from XRD profile is tabulated in table 1 . The average crystallite size of the manganese zinc ferrite systems is found to be in the range of 13.3-23.9 $\mathrm{nm}$. The substitution of zinc in $\mathrm{MnFe}_{2} \mathrm{O}_{4}$ corresponds to a linear decrease in particle size, which suggests the formation of a compositionally homogeneous solid solution. This was probably due to the reaction conditions, which favoured the formation of new nuclei preventing further growth of particles

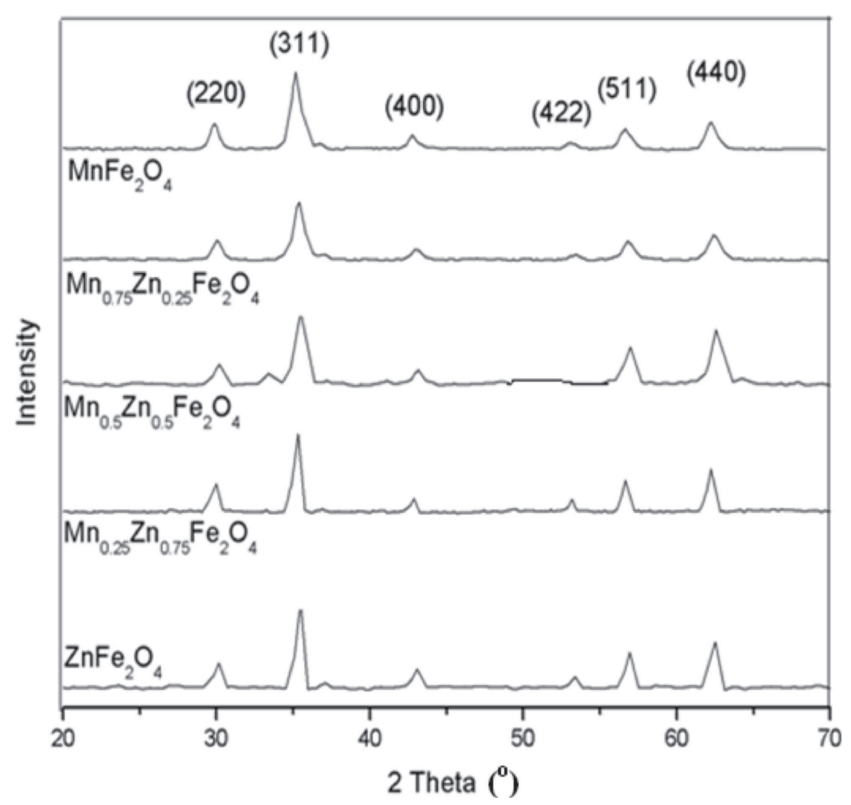

Figure 1. $\mathrm{X}$-ray profile of $\mathrm{Mn}_{\mathrm{x}} \mathrm{Zn}_{(1-\mathrm{x})} \mathrm{Fe}_{2} \mathrm{O}_{4}(\mathrm{x}=0.0,0.25$, $0.5,0.75,1.0)$. 
Table 1. Data on crystallite size (D), lattice constant (a), X-ray density $\left(d_{x}\right)$, bulk density $\left(\mathrm{d}_{\mathrm{B}}\right)$ and porosity $(\mathrm{P})$ of the prepared ferrite samples obtained from X-ray diffractograms.

\begin{tabular}{lcccccc}
\hline \multirow{2}{*}{ Sample } & \multicolumn{2}{c}{ Crystallite size D (nm) } & & & & \\
\cline { 2 - 5 } & XRD & TEM & 'a' $(\AA)$ & $d_{x}\left(\mathrm{~g} / \mathrm{m}^{3}\right)$ & $\mathrm{d}_{\mathrm{B}}\left(\mathrm{g} / \mathrm{m}^{3}\right)$ & $\mathrm{P}(\%)$ \\
\hline $\mathrm{MnFe}_{2} \mathrm{O}_{4}$ & 23.9 & $21 \pm 1$ & 8.31 & 5.34 & 3.24 & 39.32 \\
$\mathrm{Mn}_{0.75} \mathrm{Zn}_{0.25} \mathrm{Fe}_{2} \mathrm{O}_{4}$ & 13.5 & $20 \pm 1$ & 8.35 & 5.32 & 2.98 & 43.98 \\
$\mathrm{Mn}_{0.5} \mathrm{Zn}_{0.5} \mathrm{Fe}_{2} \mathrm{O}_{4}$ & 13.3 & $19 \pm 1$ & 8.37 & 5.34 & 3.06 & 42.69 \\
$\mathrm{Mn}_{0.25} \mathrm{Zn}_{0.75} \mathrm{Fe}_{2} \mathrm{O}_{4}$ & 15.9 & $17 \pm 1$ & 8.40 & 5.34 & 3.25 & 39.13 \\
$\mathrm{ZnFe}_{2} \mathrm{O}_{4}$ & 23.1 & $14 \pm 2$ & 8.43 & 5.33 & 4.01 & 24.71 \\
\hline
\end{tabular}

when the zinc concentration was increased. Vegard's law is a linear relation correlating the lattice parameters and the composition of the solid solution. ${ }^{14}$ Lattice parameter increases linearly within the range of 8.31$8.43 \AA$, with an increase in concentration of zinc, obeying Vegard's law. The observed lattice parameter is higher for $\mathrm{ZnFe}_{2} \mathrm{O}_{4}$ which could be attributed to the replacement of smaller sized iron cation by larger sized zinc cation. As a result, the size of the unit cell is increased. X-ray density, bulk density and porosity of different compositions do not show any significant change with zinc content.

The particle size obtained from X-ray diffraction profile is generally larger than the size obtained from Transmission Electron Micrographs because X-ray intensity is proportional to the average particle volume, while the particle size obtained from TEM images represents the average radius. Moreover, the size distributions obtained from TEM images are restricted to primary particles and do not include secondary particles formed by epitaxial attachment. Secondary particles are formed from integer multiples of primary particles and can have a significant influence on the volume distribution, even at relatively low concentration. ${ }^{15}$ Transmission Electron Micrographs of the prepared $\mathrm{Mn}_{1-\mathrm{x}} \mathrm{Zn}_{\mathrm{x}} \mathrm{Fe}_{2} \mathrm{O}_{4}$ samples are given in figure 2 (a-e). The particle size data and their distribution can be obtained by histogram method by counting more than 20 particles from each micrograph and representing in a graphical format. In this method, the particle size and its distribution is presented in the form of a numberfrequency histogram. ${ }^{16}$ Figure 3 (a-e) shows the number frequency histograms of particle size data of different compositions of $\mathrm{Mn}$ and $\mathrm{Zn}$ in linear scale. An advantage of this kind of plotting method is that it is easier to find a better distribution of nanoparticles. From histogram method, it is found that the particle size of different compositions of manganese and zinc ferrite nanocatalysts vary between $12-22 \mathrm{~nm}$ and particle size vary linearly with increase in manganese concentration (table 1).
Elemental composition analysis of the synthesized ferrite nanocatalysts is important since the nature and the concentration of different elements present can determine the surface morphology which in turn can affect their catalytic activities. The experimental and expected values regarding the stoichiometry of manganese zinc ferrite catalysts using X-ray fluorescence (XRF) studies are tabulated in table 2. It is clear from the table that the elemental composition of $\mathrm{Mn}_{0.25} \mathrm{Zn}_{0.75} \mathrm{Fe}_{2} \mathrm{O}_{4}, \mathrm{Mn}_{0.5} \mathrm{Zn}_{0.5} \mathrm{Fe}_{2} \mathrm{O}_{4}$ and $\mathrm{Mn}_{0.75} \mathrm{Zn}_{0.25}$ $\mathrm{Fe}_{2} \mathrm{O}_{4}$ are not in close agreement with their desired composition. This is an anomalous behaviour in comparison with the results obtained in the case of cobalt substitution in $\mathrm{ZnFe}_{2} \mathrm{O}_{4}$ which is explained in our previous paper. ${ }^{17}$ In the present case, a large discrepancy is observed between the experimental and expected values of $\mathrm{Mn}_{0.25} \mathrm{Zn}_{0.75} \mathrm{Fe}_{2} \mathrm{O}_{4}, \mathrm{Mn}_{0.5} \mathrm{Zn}_{0.5} \mathrm{Fe}_{2} \mathrm{O}_{4}$ and $\mathrm{Mn}_{0.75} \mathrm{Zn}_{0.25} \mathrm{Fe}_{2} \mathrm{O}_{4}$ samples. This may be due to the fact that substitution of $\mathrm{Mn}$ in $\mathrm{ZnFe}_{2} \mathrm{O}_{4}$ is found to be difficult due to the significant variation in atomic radii of manganese and zinc.

\subsection{Effect of reaction variables in the wet peroxide oxidation of 4-chlorophenol}

The reaction variables like temperature, 4-chlorophenol concentration, catalyst concentration and oxidant concentration can affect the oxidation activity of the catalysts to a considerable extent. Hence, the effect of these variables was studied in detail using $\mathrm{Mn}_{0.25} \mathrm{Zn}_{0.75} \mathrm{Fe}_{2} \mathrm{O}_{4}$ as the reference catalyst. The stability of the catalysts towards the reaction conditions as well as the extent of iron leaching into the aqueous medium were also investigated.

The influence of initial concentration of 4-chlorophenol in water was studied by keeping the amount of catalyst as $500 \mathrm{mg} / \mathrm{L}$, hydrogen peroxide as $4 \mathrm{~mL}$ and time as $75 \mathrm{~min} .25 \mathrm{~mL}$ solutions of 4-chlorophenol with concentration ranging from $0.75-1.75 \mathrm{~g} / \mathrm{L}$ were used. The results of the study conducted at $70^{\circ} \mathrm{C}$ are given in figure $4 \mathrm{a}$. As expected, complete degradation of 


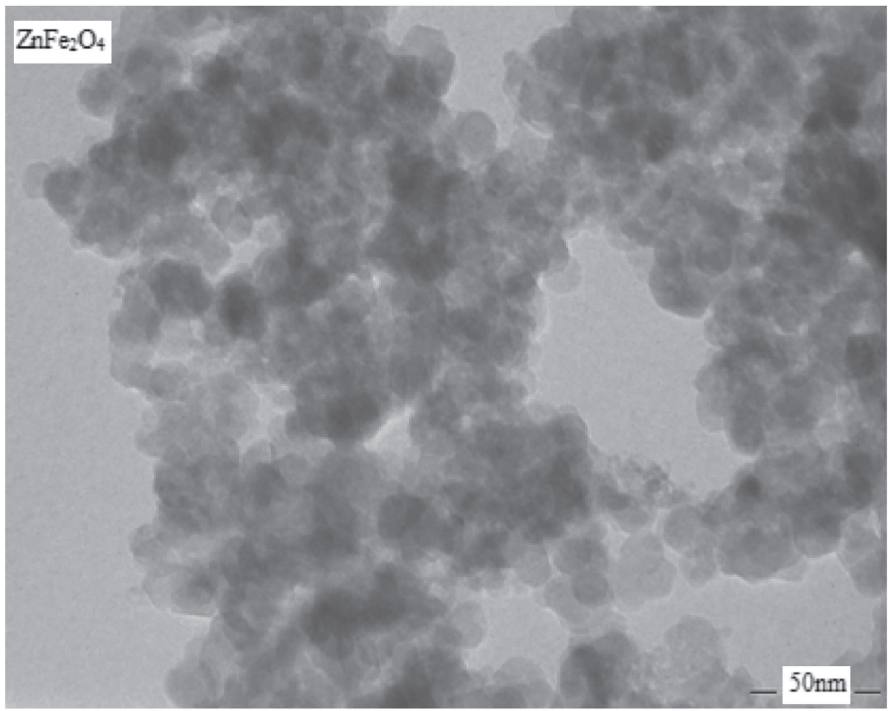

(a)

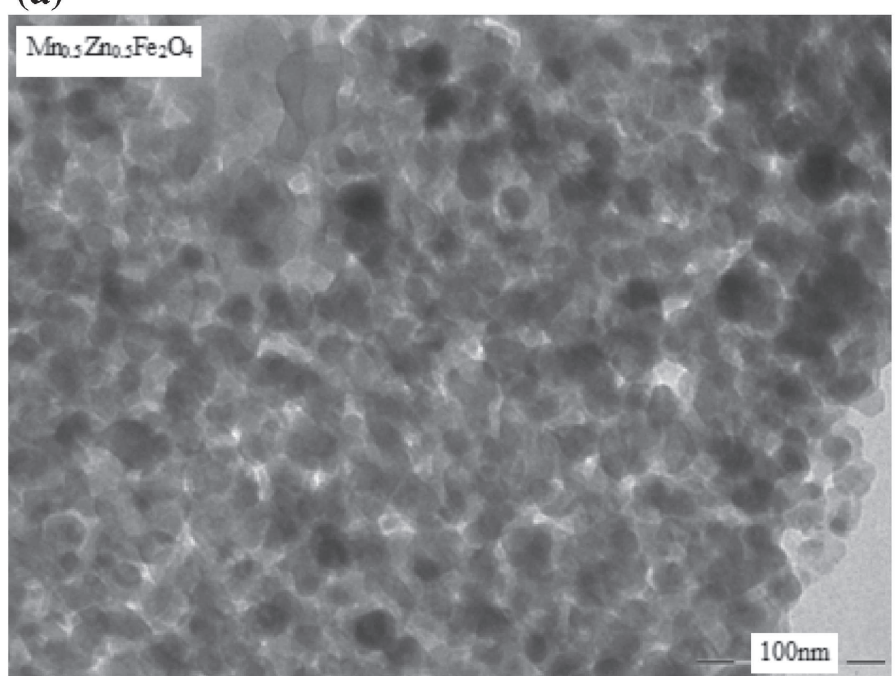

(c)

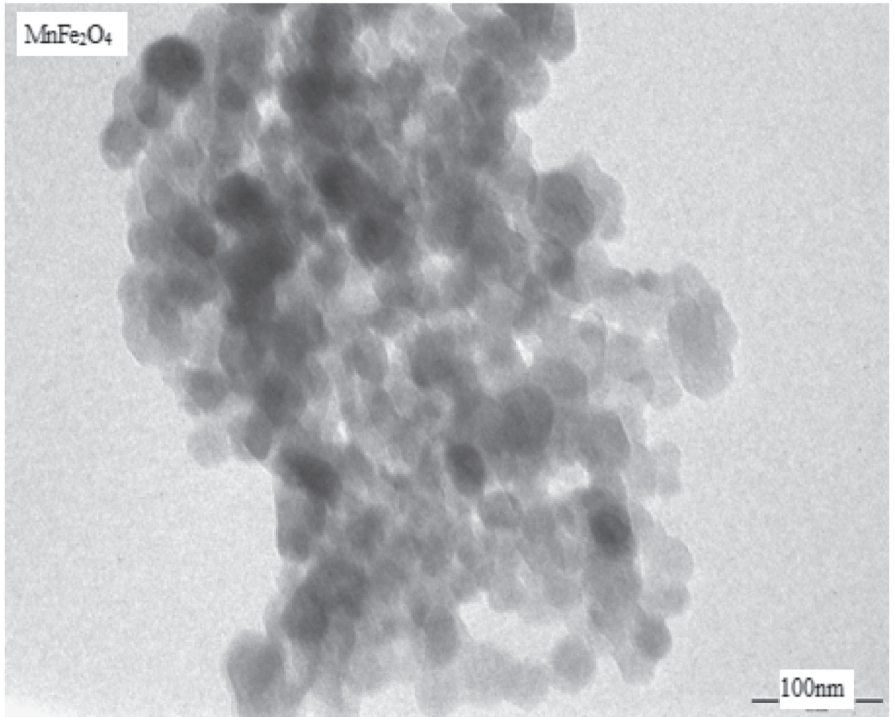

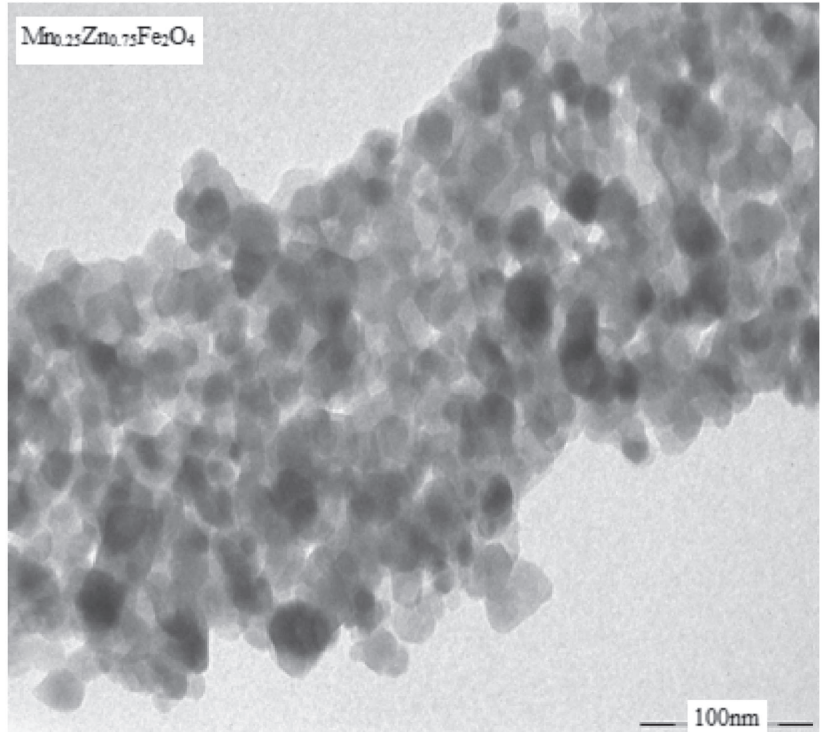

(b)

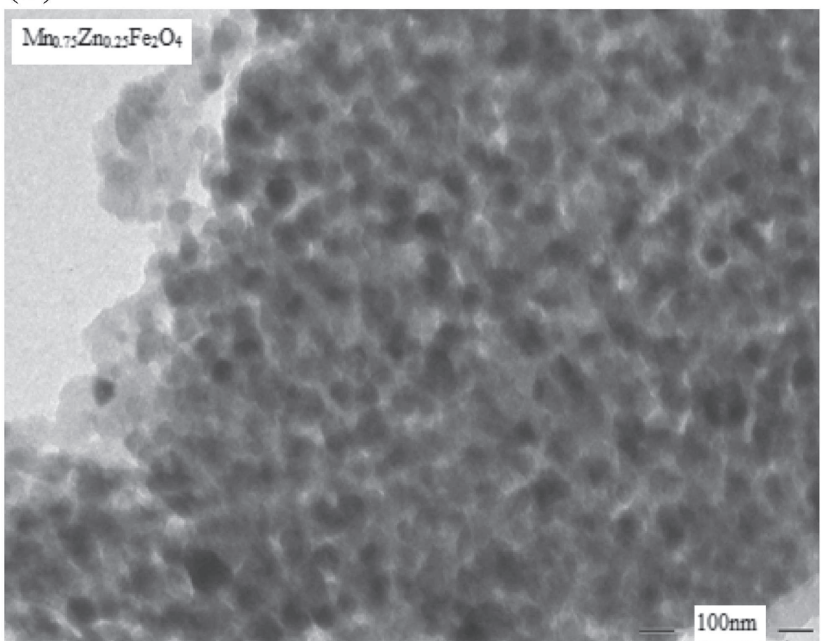

(d)

(e)

Figure 2. (a-e). Transmission Electron Micrographs of $\mathrm{Mn}_{\mathrm{x}} \mathrm{Zn}_{(1-\mathrm{X})} \mathrm{Fe}_{2} \mathrm{O}_{4}(\mathrm{x}=0.0,0.25,0.5,0.75,1.0)$ nanoparticles. 

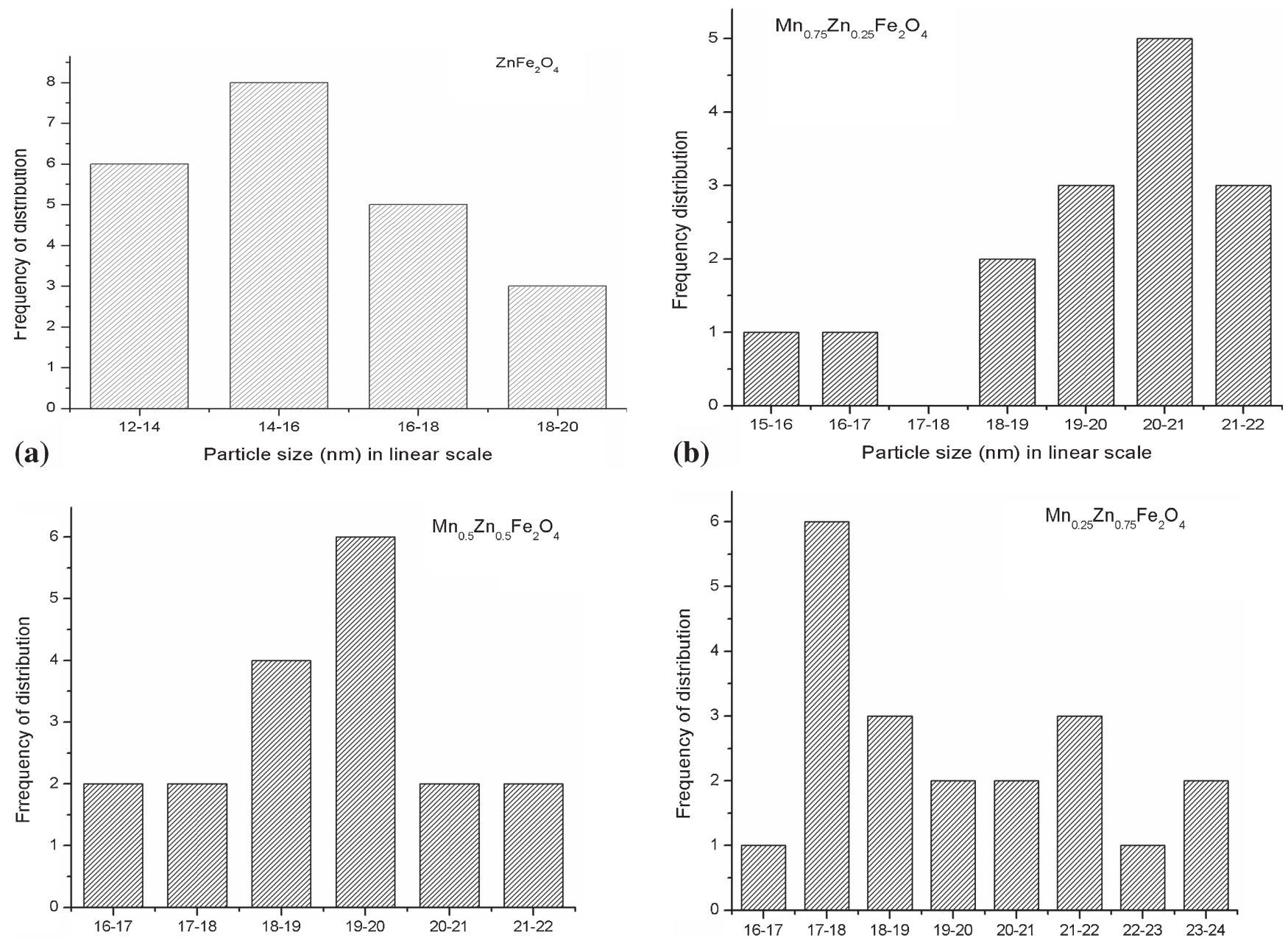

(c)

Particle size $(\mathrm{nm})$ in linear scale
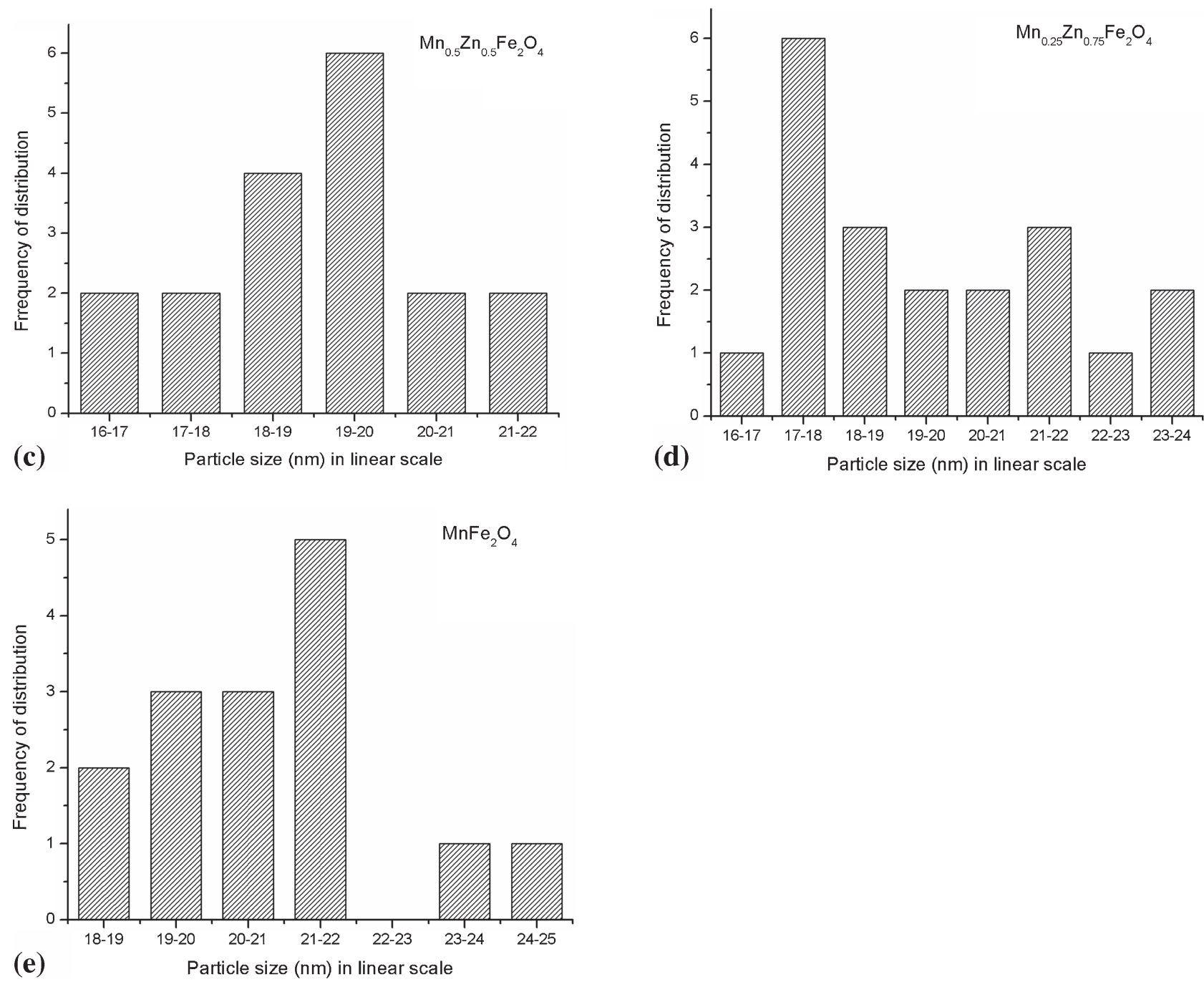

Figure 3. (a-e). TEM-Histograms of $\mathrm{Mn}_{\mathrm{x}} \mathrm{Zn}_{(1-\mathrm{x})} \mathrm{Fe}_{2} \mathrm{O}_{4}(\mathrm{x}=0.0,0.25,0.5,0.75,1.0)$ nanoparticles.

4-chlorophenol occurs at low concentrations. Increase in the target compound concentration decreases the degradation rate. These results are supported by COD measurements. The decrease in chlorophenol conversion at high concentrations can be attributed to the fact that conversions are calculated as weight percentage of unreacted chlorophenol.

A series of wet peroxide oxidations were performed in the temperature range of $25-70^{\circ} \mathrm{C}$ keeping the amount of catalyst as $500 \mathrm{mg} / \mathrm{L}$ and hydrogen peroxide 
Table 2. Elemental composition of $\mathrm{Mn}_{\mathrm{x}} \mathrm{Zn}_{1-\mathrm{x}} \mathrm{Fe}_{2} \mathrm{O}_{4}$ (x-0.0, 0.25, 0.5, 0.75, 1.0) nanoparticles by X-Ray Fluorescence spectroscopy.

\begin{tabular}{|c|c|c|c|c|c|c|c|c|}
\hline \multirow[b]{2}{*}{ Catalyst } & \multicolumn{4}{|c|}{ Experimental value } & \multicolumn{4}{|c|}{ Expected value } \\
\hline & $\mathrm{Zn}$ & $\mathrm{Mn}$ & $\mathrm{Fe}$ & $\mathrm{O}$ & $\mathrm{Zn}$ & $\mathrm{Mn}$ & $\mathrm{Fe}$ & $\mathrm{O}$ \\
\hline $\mathrm{ZnFe}_{2} \mathrm{O}_{4}$ & 0.99 & 0 & 1.99 & 4 & 1 & 0 & 2 & 4 \\
\hline $\mathrm{Mn}_{0.25} \mathrm{Zn}_{0.75} \mathrm{Fe}_{2} \mathrm{O}_{4}$ & 0.12 & 0.92 & 1.97 & 3.99 & 0.75 & 0.25 & 2 & 4 \\
\hline $\mathrm{Mn}_{0.5} \mathrm{Zn}_{0.5} \mathrm{Fe}_{2} \mathrm{O}_{4}$ & 0.36 & 0.66 & 1.99 & 3.99 & 0.5 & 0.5 & 2 & 4 \\
\hline $\mathrm{Mn}_{0.75} \mathrm{Zn}_{0.25} \mathrm{Fe}_{2} \mathrm{O}_{4}$ & 0.35 & 0.65 & 2.0 & 4.0 & 0.75 & 0.25 & 2 & 4 \\
\hline $\mathrm{MnFe}_{2} \mathrm{O}_{4}$ & 0 & 0.83 & 2.1 & 4.0 & 0 & 1 & 2 & 4 \\
\hline
\end{tabular}

as $4 \mathrm{~mL}$. Figure $4 \mathrm{~b}$ represents the influence of reaction temperature on chlorophenol conversion and COD removal at $75 \mathrm{~min}$. It can be observed that temperature has a marked influence on target pollutant removal. The catalytic efficiency is more pronounced even at lower temperatures. At $25^{\circ} \mathrm{C}$, conversion of chlorophenol is above $90 \%$. However, the COD removal is in the range of $35-55 \%$, indicating the presence of persistent organic intermediates in the reaction mixture.

Adjusting the oxidant dose is a critical feature in wet peroxide oxidation processes since $\mathrm{H}_{2} \mathrm{O}_{2}$ consumption is a determining component of the treatment cost. The effect of oxidant dosage was resolved by changing the amount of oxidant in the range of $1-5 \mathrm{~mL}$ and keeping the amount of catalyst constant as $500 \mathrm{mg} / \mathrm{L}$. Figure $4 \mathrm{c}$ depicts the results in $75 \mathrm{~min}$ at $70^{\circ} \mathrm{C}$. It can be observed that as the dosage of oxidizing agent increases, higher target pollutant removal is achieved. The results from GC analysis are substantiated by COD results as well. In the present study, only small amounts of the oxidant (3-4 mL) are required for complete degradation of 4-chlorophenol, compared toreported literature, ${ }^{18}$ thus reducing the cost of treatment process. Again, at lower oxidant concentrations, COD removal is low, indicating the presence of intermediates persisting in the reaction mixture that gets oxidized at higher oxidant dosages. The increase in oxidant concentration has been reported to increase the deep oxidation of produced intermediates to polymeric products. The high concentration of hydrogen peroxide can also accelerate selfdecomposition of the oxidant, reducing the conversion
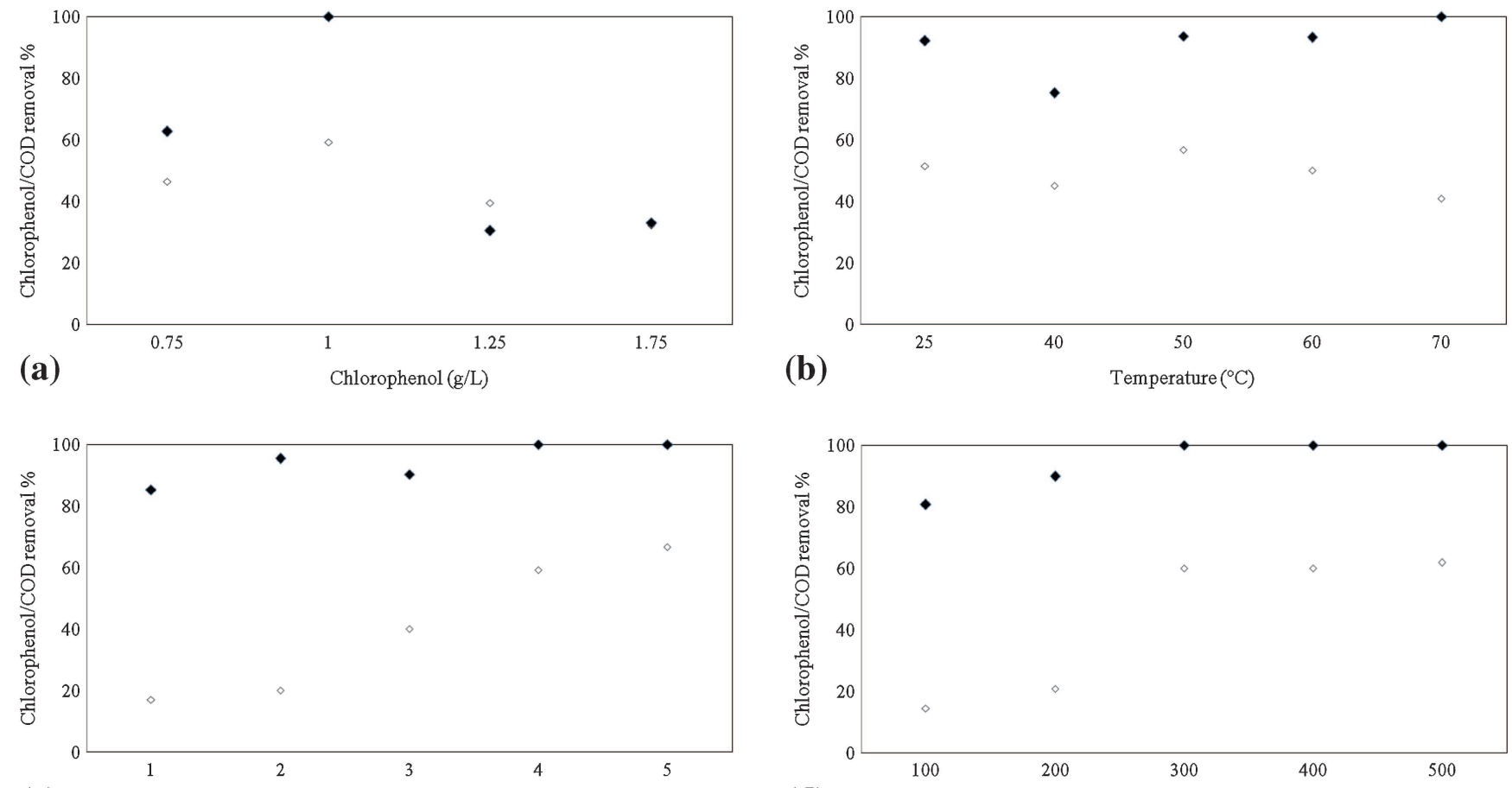

(c)

Hydrogen Peroxide (ml)

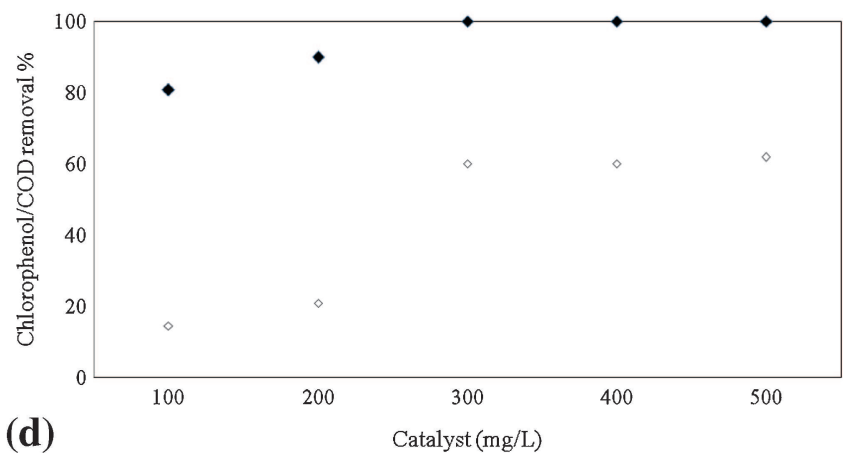

Figure 4. Efficiency of catalytic oxidation of chlorophenol under reaction conditions: Catalyst $500 \mathrm{mg} / \mathrm{L}, \mathrm{H}_{2} \mathrm{O}_{2}(30 \%$ v/v)$4 \mathrm{~mL}$, chlorophenol- $1 \mathrm{~g} / \mathrm{L}(25 \mathrm{~mL})$, Temperature- $70^{\circ} \mathrm{C}$. Variation of, (a) chlrophenol, (b) Temperature, (c) Hydrogen peroxide $30 \%(\mathrm{v} / \mathrm{v})$ and (d) catalyst. Filled markers represent \% removal of chlorophenol from GC and unfilled markers represent $\%$ removal of COD. 
of chlorophenol. Several authors have reported decrease in the reaction rate at high oxidant concentrations. ${ }^{19,20}$ However, this effect is not observed in the present case.

The concentration of catalyst used for the liquid phase wet peroxide oxidation is an important parameter determining the efficiency of the catalyst. The results of the studies on the influence of catalyst concentration at $70^{\circ} \mathrm{C}$ in $75 \mathrm{~min}$, by keeping the amount of hydrogen peroxide as $4 \mathrm{~mL}$ is given in figure $4 \mathrm{~d}$. It can be seen that there is a direct correlation between the amount of catalyst present and the extent of degradation of 4-chlorophenol. More than $80 \%$ of the target pollutant is removed at low catalyst concentrations of even $100 \mathrm{mg} / \mathrm{L}$. However, at low catalyst concentrations, the reduction in COD is only about $15-30 \%$ indicating the presence of organic degradation products persisting in the system. The symbiotic dependence between efficiency and catalytic mass indicates that the process runs on the surface of the catalyst. Having in mind that the experiments are carried out with catalyst fractions of nanometric size, it can be assumed that the outer surface of the catalyst grain is used to a great extent. In many reports there was a negative dependence of rate on catalyst concentration suggesting the occurrence of termination steps on the catalyst surface. ${ }^{21,22}$ However, this was not observed in the present case.

The experimental conditions optimized for economical, complete and efficient removal of target pollutant from water are 4-CP $(1 \mathrm{~g} / \mathrm{L})$ to hydrogen peroxide in the ratio of $25 \mathrm{~mL}$ to $4 \mathrm{~mL}$, catalyst dosage, $0.5 \mathrm{~g}$ and temperature, $70^{\circ} \mathrm{C}$.

\subsection{Effect of time in the WPO of 4-CP}

The objective of this experimental research is to evaluate the efficiency of mixed manganese zinc ferrites towards wet peroxide oxidation of organic pollutants taking 4- chlorophenol as the model compound. The catalytic activity of different compositions of nanoferrites towards the degradation of 4-chlorophenol with hydrogen peroxide was studied by keeping the amount of catalyst as $500 \mathrm{mg} / \mathrm{L}$ and hydrogen peroxide as $4 \mathrm{~mL}$. The results of the investigation at $70^{\circ} \mathrm{C}$ are presented in figure 5. Complete degradation of 4chlorophenol occurs within $90 \mathrm{~min}$ with the catalysts under study. Zinc substitution enhances the catalytic efficiency of manganese ferrite and the unsubstituted $\mathrm{ZnFe}_{2} \mathrm{O}_{4}$ oxidises the target compound completely within $45 \mathrm{~min}$. This trend in oxidation activity was followed by COD measurements of the reaction mixture also. COD is a more important parameter than chlorophenol conversion since it measures the contaminant abatement considering the toxic nature of

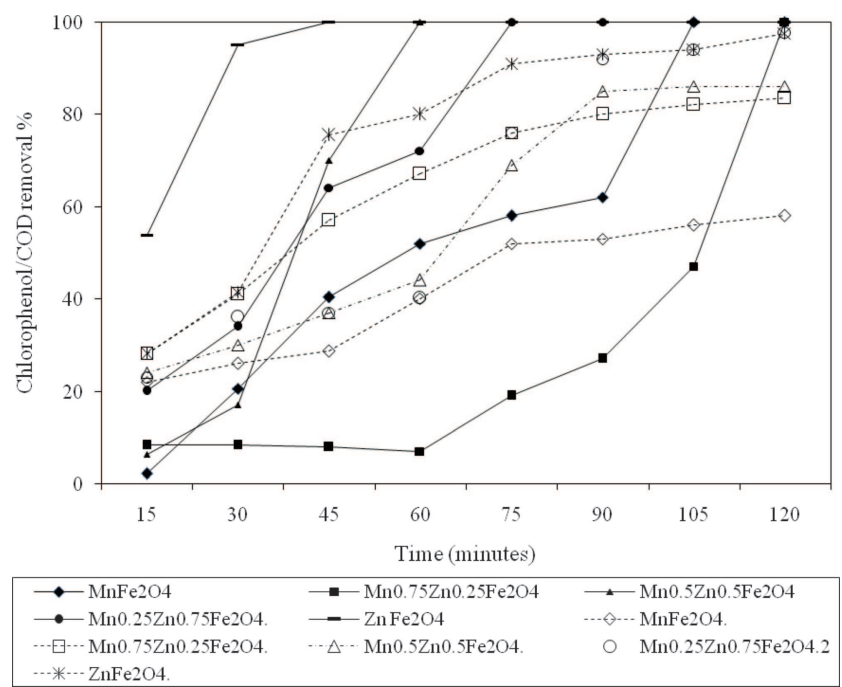

Figure 5. Wet peroxide oxidation of 4-chlorophenol over $\mathrm{Mn}_{\mathrm{x}} \mathrm{Zn}_{(1-\mathrm{x})} \mathrm{Fe}_{2} \mathrm{O}_{4}(\mathrm{x}=0.0,0.25,0.5,0.75,1.0)$. Reaction Conditions: $\mathrm{H}_{2} \mathrm{O}_{2}(30 \% \mathrm{v} / \mathrm{v})-4 \mathrm{~mL}$, catalyst- $500 \mathrm{mg} / \mathrm{L}$, chlorophenol- $1 \mathrm{~g} / \mathrm{L}(25 \mathrm{~mL})$, Temperature- $70^{\circ} \mathrm{C}$. Filled markers represent \% removal of chlorophenol from GC and unfilled markers joined by dotted lines represent $\%$ removal of COD.

the intermediates and products formed. The results of COD measurements confirm the results obtained by $\mathrm{GC}$ analysis. Another significant observation from the figure is that the degradation of 4-chlorophenol and COD reduction is slow during the initial periods of the reaction and as time advances, it accelerates. Generally, catalysed wet oxidations present similar features in concentration-time profiles. In several applications, these processes have a slow conversion rate in the initial induction period followed by a faster stage finally increasing to total degradation of organic compounds. The initial induction period is attributed to the time necessary to reach a critical concentration of organic radicals.

Ferrites are ceramic ferromagnetic materials with general chemical formula $\mathrm{MFe}_{2} \mathrm{O}_{4}$ where $\mathrm{M}$ represents a metallic cation like $\mathrm{Fe}, \mathrm{Mn}, \mathrm{Mg}, \mathrm{Ni}, \mathrm{Co}, \mathrm{Zn}, \mathrm{Cu}, \mathrm{Al}$ or a mixture of these. They crystallize into the spinel structure in which, the sites occupied by the cations are of two types: tetrahedral (A) and octahedral (B) sites. Based on the partial occupancy of these sites, spinels are divided into three; a) normal spinel in which M occupies A sites and Fe, B sites, b) inverse spinel in which $\mathrm{M}$ occupies $\mathrm{B}$ sites together with half of $\mathrm{Fe}$ atoms, the other half being on A sites and c) mixed or random spinel in which both $\mathrm{M}$ and $\mathrm{Fe}$ occupy both $\mathrm{A}$ and $\mathrm{B}$ sites. In spinel ferrites the octahedral sites, rather than tetrahedral sites are more exposed in the outer surface and hence the octahedral cations are considered to be responsible for catalytic activity, which is 
essentially a surface phenomena. $\mathrm{ZnFe}_{2} \mathrm{O}_{4}$ is a normal spinel in which the tetrahedral sites are filled by $\mathrm{Zn}^{2+}$ ions and the octahedral sites by $\mathrm{Fe}^{3+}$ ions exclusively. It can be safely deduced that $\mathrm{Fe}^{3+} / \mathrm{Fe}^{2+}$ redox couple plays a significant role in the wet peroxide oxidation reactions and hence the higher activity of $\mathrm{ZnFe}_{2} \mathrm{O}_{4}$. However, in mixed spinel ferrites, as the concentration of the divalent metal ions increases, it gives rise to changes in cation distribution in the crystal lattice without affecting the spinel ferrite structure. With progressive addition of $\mathrm{Mn}$ to $\mathrm{ZnFe}_{2} \mathrm{O}_{4}$, the normal spinel structure gets converted to inverse spinel structure in which $\mathrm{Mn}^{2+}$ ions partially substitute the $\mathrm{Fe}^{3+}$ ions in the octahedral sites. The substitution of $\mathrm{Mn}$ into the spinel structure of $\mathrm{ZnFe}_{2} \mathrm{O}_{4}$ is very small as confirmed by X-ray fluorescence. The replacement of active $\mathrm{Fe}^{3+}$ ions by $\mathrm{Mn}^{2+}$ ions occurs to a small extent only and hence the catalytic activity is not much affected by manganese substitution giving almost similar reduction in COD value (figure 5). Also, redox nature of $\mathrm{Mn}$ is considerably low compared to $\mathrm{Fe}$, the oxidation activity decreases with successive addition of $\mathrm{Mn}$ to $\mathrm{ZnFe}_{2} \mathrm{O}_{4}$.

Wet peroxide oxidation of chlorophenols has been reported to occur over several catalysts. AlFe pillared clays gave $70 \%$ removal of 4 -chlorophenol at $50^{\circ} \mathrm{C}$ when a $125 \mathrm{ppm}$ aqueous solution was used. ${ }^{6} 2 \mathrm{mM}$ solution of 4- chlorophenol was completely degraded using hydrotalcite/clay composite using $40 \mathrm{mM} \mathrm{H}_{2} \mathrm{O}_{2}$ at $40^{\circ} \mathrm{C}^{1}$. Complete removal of 4-chlorophenol occurred at $100^{\circ} \mathrm{C}$ with $2.5 \mathrm{~cm}^{3}$ of $\mathrm{H}_{2} \mathrm{O}_{2}$ and an initial concentration of $500 \mathrm{ppm}$ after $90 \mathrm{~min}$ in the absence of a catalyst. ${ }^{23}$ Several compounds like naphthalene, flourene, acenaphthalene, chrysene, etc., have been reported as products in wet peroxide oxidation of 4-chlorophenol in literature. ${ }^{9,22}$ Zhou et al. reported benzoquinone and the chlorinated benzoquinones as intermediate products. ${ }^{1}$ In our study, triacetone peroxide is the major intermediate identified by GC MS analysis. Other products observed in traces are acetone, 4 hydroxy 4 methyl 2 pentanone, 2,5 hexane dione, xylenes and benzoquinone. The presence of triacetone peroxide can be due to the conversion of acetone by excess hydrogen peroxide present in the reaction mixture, which produces the polymer in presence of acidic catalysts like ferrites. Thus, the target pollutant is completely removed as simple organic intermediates which in turn are oxidized completely.

\subsection{Stability of the catalyst}

Catalytic stability is an important factor of continuing concern for industrial applications and was given utmost importance in the present study. The presence
Table 3. Stability of catalyst towards wet peroxide oxidation.

\begin{tabular}{lccc}
\hline $\begin{array}{l}\text { No. of } \\
\text { cycles }\end{array}$ & $\begin{array}{c}\% \text { removal of 4-CP } \\
\text { from water }\end{array}$ & $\begin{array}{c}\text { \% reduction } \\
\text { of COD }\end{array}$ & $\begin{array}{c}\text { Amount of Fe } \\
\text { leached (ppm) }\end{array}$ \\
\hline 1 & 100 & 95.9 & 1.2 \\
2 & 100 & 94.8 & 1.1 \\
3 & 100 & 94.5 & 3.2 \\
4 & 100 & 91.8 & 3.7 \\
5 & 100 & 84.8 & 4.5 \\
\hline
\end{tabular}

Reaction Conditions: Catalyst- $\mathrm{Mn}_{0.25} \mathrm{Zn}_{0.75} \mathrm{Fe}_{2} \mathrm{O}_{4}, \mathrm{H}_{2} \mathrm{O}_{2}$ $(30 \% \mathrm{v} / \mathrm{v})-4 \mathrm{~mL}$, catalyst- $500 \mathrm{mg} / \mathrm{L}$, chlorophenol- $1 \mathrm{~g} / \mathrm{L}$ $(25 \mathrm{~mL})$, Temperature- $70^{\circ} \mathrm{C}$

of strongly adsorbed reaction products or by-products can block part of the surface, thus producing a genuine deactivation which ultimately favours surface over oxidation resulting in a much greater deactivation. ${ }^{24,25}$ Hence, the reusability of the prepared systems was checked by retaining a catalyst batch and using it for several cycles without treatment between cycles. The catalyst and reactants were placed in the reactor following the procedure previously described. It is interesting to note that the activity of the catalysts remains the same after five successive runs (table 1). The catalyst removed about $85 \%$ of the COD even on its fifth cycle.

Application of heterogeneous catalysts in purification of waste water requires that they be stable towards metal ion exchange between the catalyst and the liquid phase under the operating conditions. Continuous and gradual leaching can lead to deactivation of the catalyst. It is also important to make sure that the reaction as well as the catalysts do not cause any kind of further pollution in water. Leaching studies are also valuable in the sense that they can provide insights to the mechanism of the reaction, whether homogeneous or heterogeneous. The iron concentration in the liquid phase after one hour reaction was repeatedly measured using Atomic Absorption Spectrometer and the results are presented in table 3. For manganese zinc ferrite nanoparticles, the amount of iron leached remains about $1 \mathrm{ppm}$ in two consecutive runs and then it increases to about $4 \mathrm{ppm}$. It can be concluded that iron leaching is fairly low after five consecutive cycles indicating the mechanism to be heterogeneous.

\section{Conclusions}

Wet Peroxide Oxidation appears to be a promising technology for the removal of chlorophenols from waste water since complete removal of the target compound can be achieved at mild conditions $\left(70^{\circ} \mathrm{C}, 4 \mathrm{~mL}\right.$ of 
$\mathrm{H}_{2} \mathrm{O}_{2}$ ). Manganese zinc ferrite nanoparticles act as efficient catalysts for the oxidation of 4-chlorophenol in presence of hydrogen peroxide as oxidant. Complete removal of the target compound was achieved within $45 \mathrm{~min}$ at $70^{\circ} \mathrm{C}$ over zinc ferrite catalyst with more than $99 \%$ reduction in COD. Only small amounts of the oxidant $(3-4 \mathrm{~mL})$ are required for complete degradation of 4-chlorophenol, thus reducing the cost of treatment process. Direct correlation exists between the amount of catalyst present and the extent of degradation of 4-chlorophenol ruling out the heterogeneoushomogeneous mechanism. More than $80 \%$ of the target pollutant was removed at a catalyst concentration as low as $100 \mathrm{mg} / \mathrm{L}$. The catalysts are reusable after five successive runs. The extent of iron leaching is fairly low after five consecutive cycles indicating that the mechanism is heterogeneous.

\section{Acknowledgement}

Financial assistance from the Department of Science and Technology, India through Fast Track Scheme for Young Scientists is gratefully acknowledged.

\section{References}

1. Zhou S, Gu C, Qian Z, Xu J and Xia C 2011 J. Colloid Interface Sci. 357447

2. Kurian M, Joy M and Raj D 2012 J. Porous Mater. 19 633

3. Kwon B G, Lee D S, Kang N and Yoon J 1999 Water Res. 332110

4. Lu M 2000 Chemosphere $\mathbf{4 0} 125$
5. Kurian M, Eldhose A and Thasleenabi R M 2012 Inter. J. Environ. Res. 6669

6. Catrinescu C, Arsene D and Teodosiu C 2011 Appl. Catal. B: Environ. 101451

7. Kaith L H and Telliard W A 1979 Environ. Sci. Technol. 13416

8. Terada H 1990 Environ. Health Perspect. 87213

9. Wang J H, Liu Y C, Liu D C, Yu Y W and Guo F B 2009 J. Magn. Magn. Mater. 3213646

10. Silva V J, Cornejo D R, Morelli M R and Gama L 2008 J. Magn. Magn. Mater. 320370

11. Ramankutty C G, Sugunan S and Thomas B 2002 J. Mol Catal A: Chem. 187105

12. Dent Glasser L S 1977 In Crystallography and Its Applications (New York: Van Nostrand Reinhold) p. 114

13. Kurian M and Nair D S 2013 J. Saudi Chem. Soc. 17345

14. Whisto C In X-ray Methods 1991 F E Prichard (Ed.) (New York: Wiley) 142

15. Ayyappan S, Mahadevan S, Chandramohan P, Srinivasan M P, Philip J and Raj B 2010 J. Phys. Chem. 1146334

16. Phokharatkul P, Chaisriya S, Somkuarnpanit S, Phaiboon S and Kimpan C 2007 Inter. J. Comput. Info. Sys. Contr. Eng. 12539

17. Kurian M and Nair D S 2014 J. Environ. Chem. Eng. 2 63

18. Hamoudi S, Sayari A, Belkacemi K, Bonneviot L and Larachi F 2000 Catal. Today 62379

19. Kurian M and Babu R 2013 J. Environ. Chem. Eng. 186

20. Sadana A and Katzer J R 1974 J. Catal. 35140

21. Kurian M and Sugunan S 2006 Chem. Eng. J. 115139

22. Lin K.S and Wang H P 2000 Langmuir 162627

23. Molina V G, Lopez Arias M, Florczyk M, Chamarro E and Esplugas S 2005 Water Res. 39795

24. Mallat T and Baiker A 1994 Catal. Today 19247

25. Forzatti P and Lietti P 1999 Catal. Today 52165 